\title{
Fast Degradation of Green Pollutants Through Nanonets and Nanofibers of the Al-Doped Zinc Oxide
}

\author{
Osama Saber $^{1,2} \cdot$ Haifa Alomair ${ }^{3} \cdot$ Mohamed Abu-Abdeen $^{1} \cdot$ Abdullah Aljaafari $^{1}$
}

Received: 6 May 2017 / Revised: 20 August 2017/Published online: 13 December 2017

(C) The Chinese Society for Metals and Springer-Verlag GmbH Germany, part of Springer Nature 2017

\begin{abstract}
In this study, series of nanolayered structures of $\mathrm{Zn}-\mathrm{Al} \mathrm{LDHs}$ were prepared by urea hydrolysis. Nanofibers and nanonets of the $\mathrm{Al}$-doped $\mathrm{ZnO}$ were formed via the decomposition of the nanolayers under high pressure and temperature. Nanospheres were also prepared for comparison. The different morphologies of the prepared nanomaterials were confirmed by several techniques. An improvement for the optical properties of the doped zinc oxides was observed through narrowing of their band gap energies because of transforming the nanolayers to nanonets and nanofibers. The photocatalytic activities of the prepared nanomaterials were studied through photocatalytic degradation of the pollutants of acid green dyes. Complete decolorization and mineralization of green dyes happened in the presence of the nanolayers and nanospheres within 4-6 h, while the nanonets and the nanofibers achieved the complete decolorization and degradation of the dyes at shorter time $1.3 \mathrm{~h}$. These results could be explained though the kinetic study of the photocatalytic degradation of dyes. It was concluded that the nanonets and the nanofibers were very effective for the photocatalytic degradation of pollutants.
\end{abstract}

Keywords Al-doped ZnO nanolayers · Nanofibers · Nanonets · Band gap energy · Photocatalytic degradation · Acid green dyes pollutants

\section{Introduction}

Nanomaterials are one of the most active growing areas of research in the fields of engineering and science. Additionally, their applications in the field of environmental remediation are very promising. Over the past decade, it has become abundantly clear that the world faces major threats to its water supplies. The most serious current universal problems are protection of water supplies, which is of high environmental importance [1]. Contamination of rivers, lakes, and oceans occurred due to the disposal of unwanted anthropogenic chemicals (or effluents) [2-4]. Textile dyes and surfactants are the main hazardous

Available online at http://link.springer.com/journal/40195

Osama Saber

osmohamed@kfu.edu.sa

1 Faculty of Science, King Faisal University, Al-Hasa 31982, P.O. Box 400, Saudi Arabia

2 Egyptian Petroleum Research Institute, P.O. Box 11727, Nasr City, Cairo, Egypt

3 Ministry of Education, Al-Hasa 31982, Saudi Arabia pollutants, because most of the organic dyes are not easily biodegradable [5-7].

Photocatalytic degradation seems to be as an emerging resolution for elimination of dyes from wastewater using light and semiconductors [8]. Among the used semiconductors, zinc oxide and titanium dioxide are established to be effective for photocatalytic degradation of pollutants $[9,10]$.

Daneshvar et al. [11] reported that the complete decay of acid red 14 was successfully achieved by the ZnO-based photocatalyst. Other researchers revealed that the photocatalytic activity of $\mathrm{ZnO}$ is higher than that of $\mathrm{TiO}_{2}$ [12, 13]. However, Wang et al. [14] and Zhou et al. [15] claimed that $\mathrm{ZnO}$ as a photocatalyst has some problems such as a low quantum yield in the photocatalytic reactions in aqueous solutions and the fast recombination rate of electron-hole pair, which obstruct commercialization of the photocatalytic degradation process. Several methods and different elements were applied and reported to solve these problems. Morphological variation in the nanoscale [16], joining with other nanomaterials, such as carbon nanotube [17], introducing surface defects [18], and doping with transition elements, were suggested as appropriate 
solutions for avoiding the disadvantages of $\mathrm{ZnO}$ photocatalyst. Among these solutions, doping with transition elements into zinc oxide has recently received much attention $[19,20]$. Zinc oxide was doped by various transition elements [21-24], such as $\mathrm{Pd}, \mathrm{Bi}, \mathrm{Sm}, \mathrm{Al}$, and $\mathrm{Ce}$ to improve its photocatalytic activity.

In this trend, the $\mathrm{Al}$-doped $\mathrm{ZnO}$ attracted our attention because of its distinctive physicochemical properties. Therefore, in our previous research [25], we concluded that the improvement of photocatalytic activity of the Al-doped $\mathrm{ZnO}$ through the photocatalytic degradation of naphthol green $\mathrm{B}$ was attributed to the reduction in its band gap because of the presence of high percentage of $\mathrm{Al}$ in the structure of $\mathrm{ZnO}$.

In the same way, construction of the Al-doped zinc oxides with organized shape and size may be a way for improving their photoactivities toward degradation of pollutants. Nanolayered structures are considered as critical way for combining two or more fundamental metals together with morphological variation in the nanoscale [26].

Layered double hydroxides (LDHs) are a large family of nanolayered structures, which can be symbolized by the common formula $\left[\mathrm{MII}_{1-x} \quad \mathrm{MIII}_{x}(\mathrm{OH})_{2}\right]^{x+}\left[\mathrm{A}^{n-}\right]_{x / n} \cdot y \mathrm{H}_{2} \mathrm{O}$. The divalent (MII) and trivalent (MIII) elements are arranged into nanolayers $(0.48 \mathrm{~nm})$ [27], and the positive charge of the nanolayers is neutralized by interlayer anions $\left(\mathrm{A}^{n-}\right)$. According to the nanolayered structures of LDHs, they exhibited promising applications in many aspects, such as adsorbents [28], photocatalysts [29], anodic materials [30], sensors [31], magnetic materials [32], and energy conversion and storage [33]. The common factor in these studies was to look for a better control of the size and shape of LDH particles, producing more efficient products for the potential applications.

Recently, although Abderrazek et al. [34] studied the photocatalytic activity of the calcined nanolayered structures of $\mathrm{Zn}-\mathrm{Al} \mathrm{LDHs}$, they followed the usual way for the calcination of the nanolayered structures and did not deal with the produced morphology of the calcined LDHs.

This study emphasized the importance of the morphology of the Al-doped $\mathrm{ZnO}$, which obtained from the thermal treatment of LDHs as effective photocatalysts for the degradation of acid green 1 (AG1) using UV light. Also, it induced a method for controlling the produced morphology of the decomposed nanolayered structures of LDHs. For this purpose, nanolayers of $\mathrm{Zn}-\mathrm{Al} \mathrm{LDHs}$ were prepared and transformed to nanonets and nanofibers of the Al-doped zinc oxides with different morphologies. The optical properties of the Al-doped zinc oxides were studied and explained according to their morphologies. Also, the photocatalytic activities of the nanolayers, nanoparticles, and nanofibers of the $\mathrm{Al}$-doped $\mathrm{ZnO}$ were measured by degradation of AG1 under UV light irradiation. Furthermore, the photocatalytic decolorization and degradation kinetics of AG1 were studied.

\section{Experimental}

\subsection{Preparation of Nanolayered Structures of Zn-AI LDHs}

Series of $\mathrm{Zn}-\mathrm{Al}$ LDHs were prepared using a co-precipitation method. Nanolayers were precipitated through urea hydrolysis by reacting aqueous solutions $(0.07 \mathrm{~mol}) \mathrm{con}$ taining a mixture of zinc nitrate and aluminum nitrate. The percentage of aluminum was increased from 5 to $30 \mathrm{wt} \%$. Urea was used as $\mathrm{pH}$-controller. By heating the mixture at $70{ }^{\circ} \mathrm{C}$, the $\mathrm{pH}$ of the aqueous solution was changed into alkaline solution. White product was precipitated and washed by distilled water. It was dehydrated at room temperature for $48 \mathrm{~h}$. For simplicity, the samples were symbolized as $\mathrm{ZnAl}-x$, where $x$ is the percentages of aluminum.

\subsection{Transformation of Nanolayers to Nanoparticles and Nanofibers}

Three grams of the prepared LDH was mixed with $150 \mathrm{ml}$ of methanol at room temperature and atmospheric pressure. A magnetic stirring was continued for $12 \mathrm{~h}$ to avoid agglomeration. Then, the mixture was placed in an autoclave with temperature and pressure controller unit. The volume of the mixture was increased to be $500 \mathrm{~mL}$ by adding ethanol. It was thermally treated at temperature of $300{ }^{\circ} \mathrm{C}$ and pressure of 90 bar (supercritical conditions). The heating rate of the autoclave was stepped up to a higher degree than the critical one. Accordingly, the pressure followed the rising of temperature to a value higher than the critical pressure. At this point, the autoclave is vented by gently opening the valve of the autoclave to reach the atmospheric pressure. In order to evacuate any residual gases, the autoclave is fluxed with argon gas. The autoclave is then cooled down to room temperature. Since the solvent vapor is changed by an inert gas, no liquid condensation arises. For simplicity, the samples were symbolized as $\mathrm{ZnAl}-x$-TP, where $x$ is the percentages of aluminum and TP means thermal treatment under high pressure.

\subsection{Characterization Techniques}

$\mathrm{X}$-ray diffraction analysis (XRD) was performed by $\mathrm{Cu}-\mathrm{K} \alpha$ radiation of Bruker-AXS, Karlsruhe, Germany $(\lambda=0.154 \mathrm{~nm})$. Energy-dispersive $\mathrm{X}$-ray spectroscopy was measured using an electron probe microanalyzer JED 2300. Fourier transform infrared spectroscopy (FTIR) was 
recorded on a PerkinElmer Spectrum 400 over the wave number range $425-4000 \mathrm{~cm}^{-1}$. Thermal gravimetric analysis was carried out by TA thermogravimetric analyzer (Q500) under nitrogen gas. TA series Q 600 was used to perform differential scanning calorimetry (DSC) analysis. Transmission electron microscopy (TEM) was used to image the samples at nanoscale with JEM 2100F. UV-Vis absorption spectra were measured through diffuse reflectance technique to express the optical absorption properties for all prepared materials by Shimadzu 3600 UV-VIS-NIR spectrophotometer.

\subsection{Photocatalytic Measurements}

The photocatalytic ability of the different prepared nanomaterials was investigated through degradation of acid green 1 (AG1). The chemical structure of AG1 is given in Scheme 1. The oxidant species that produced on the photocatalyst surface would attack and decompose the green dye of AG1 to become colorless. According to the law of Beer-Lambert [25], change in the dye concentration is proportional to the intensity of the measured spectrum of the dye when the initial concentration is low. In the present study, the AG1 $\left(4 \times 10^{-4} \mathrm{M}\right)$ solutions containing $0.1 \mathrm{~g}$ of the prepared $\mathrm{Al}$-doped $\mathrm{ZnO}$ particles were irradiated by UV light through photocatalytic reactor. The photocatalytic reactions were achieved in a cylindrical glass vessel at room temperature. The glass vessel was equipped with magnetic stirrer and cooling system as shown in Scheme 1. The glass vessel was illuminated by using 1400 -W mercury lamp (medium pressure).

The characteristic peak of AG1 is at $714 \mathrm{~nm}$, whereas the other peaks are at 320,283 , and $232 \mathrm{~nm}$ due to the phenyl groups. The extent of decomposition was calculated from the integrated area of the peak at $714 \mathrm{~nm}$. The progress of photocatalytic degradation of the pollutant was followed by withdrawing fixed amount of the solution at different intervals. Before illumination, the mixture was

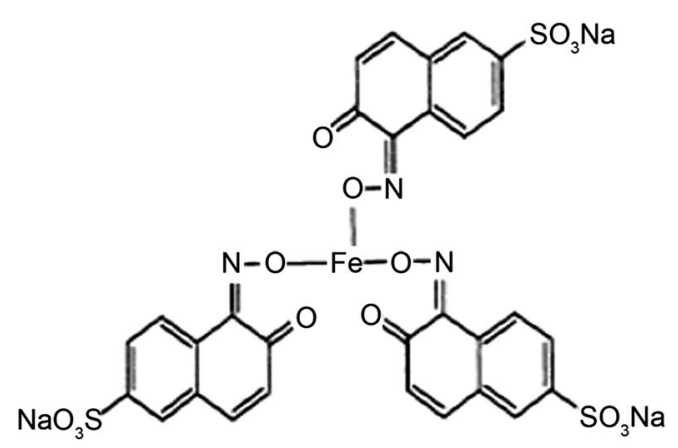

Scheme 1 Chemical formula of acid green 1 and photocatalytic reactor magnetically stirred for 30 min to reach the adsorptiondesorption equilibrium of AG1 on the catalyst. The degradation and the decolorization of the solutions were followed by determining the concentration of the remaining dye in the solutions. The concentrations of the AG1 solutions before and after irradiation were determined by measuring the absorbance using UV-vis spectrophotometer.

\section{Results}

\subsection{Characterization of $\mathrm{Zn}-\mathrm{Al}$ Nanolayered Structures}

Doping of zinc with different concentrations of aluminum was achieved through formation of $\mathrm{Zn}-\mathrm{Al}$ nanolayered structures. The XRD pattern of the sample ZnAl-30 agreed with the layered structure of the natural hydrotalcite (JCPDS file No. 37-629) and the synthetic Zn-Al LDH (JCPDS file No. 48-1022) as shown in Fig. 1a. It exhibited sharp reflection for the basal plane (003) at $d=0.76 \mathrm{~nm}$. Also, the reflections of the planes (006) and (009) were clear at $d=0.38 \mathrm{~nm}$ and $d=0.26 \mathrm{~nm}$, respectively. The clear arrangement between these values matching to successive diffractions by basal planes, i.e., $d_{(003)}=2 d_{(006)}=3 \mathrm{~d}(009)$ for $\mathrm{ZnAl}-30$, revealed highly ordered nanolayers along axis $c$. The value $c$, related to the thickness of the brucite-like layer and the interlayer distance, was calculated as three times the interlayered spacing of plane (003), i.e., $2.28 \mathrm{~nm}$. The $c$ dimension was identical to that reported for the natural and synthetic hydrotalcite, $2.28 \mathrm{~nm}$. The lattice parameter $a$, calculated as two times of the spacing for plane (110), was $0.308 \mathrm{~nm}$. It corresponded to the average distance among cations within the layer. Three weak reflections when $d=0.69,0.46$, and $0.33 \mathrm{~nm}$ were observed. These reflections indicated that hydrozincite phase $\mathrm{Zn}_{5}(-$ $\mathrm{OH})_{6}\left(\mathrm{CO}_{3}\right)_{2}$ started to grow.

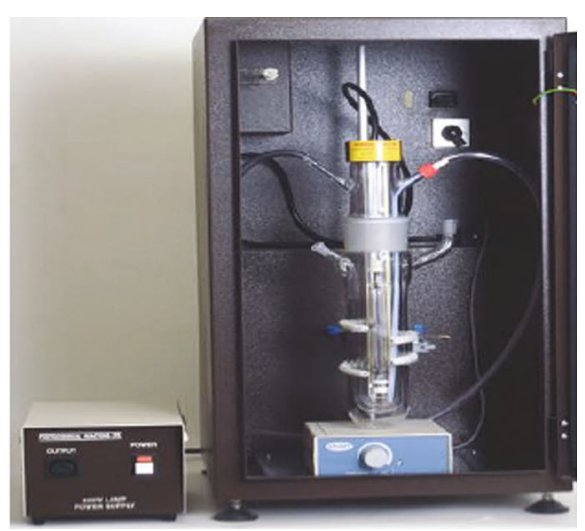




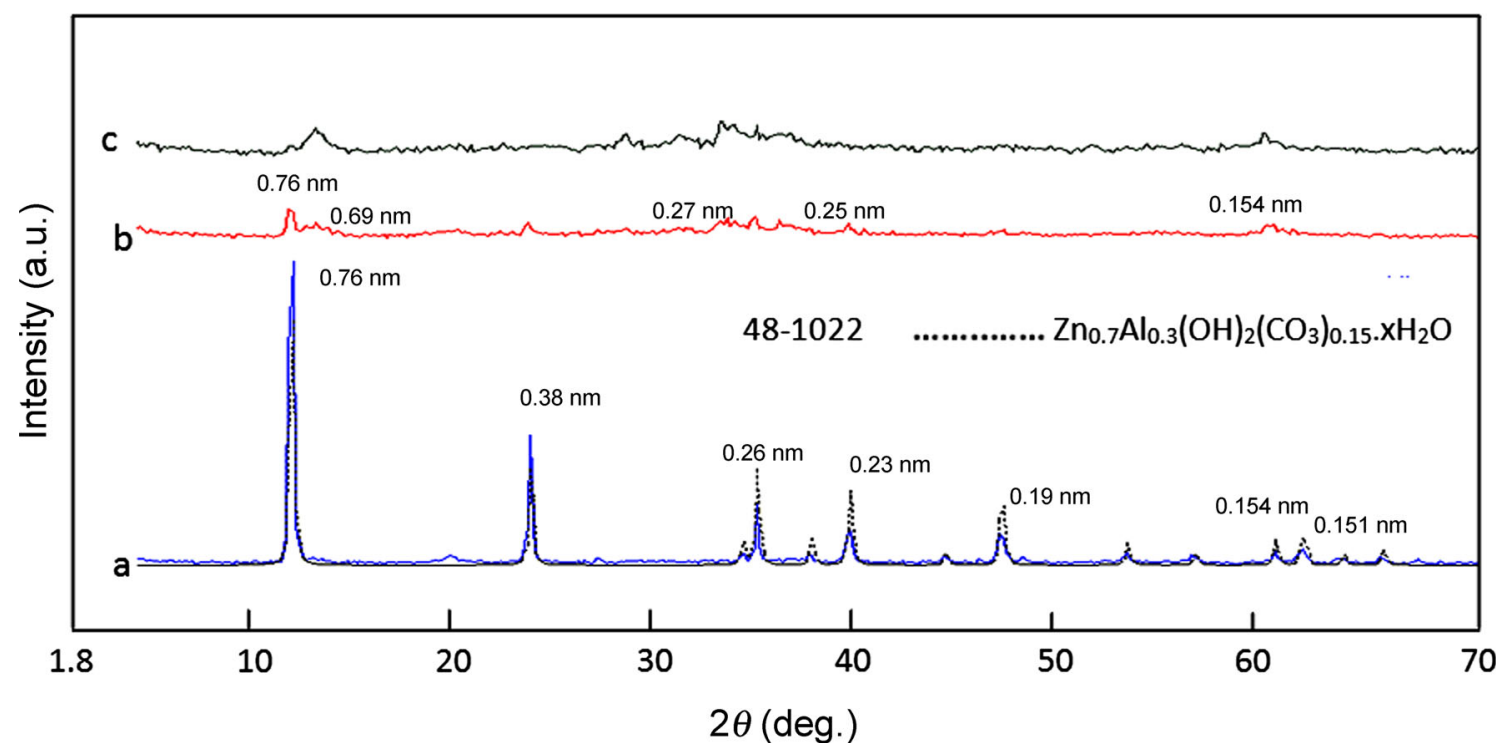

Fig. 1 XRD patterns of: $a \mathrm{ZnAl}-30, b \mathrm{ZnAl}-15, c \mathrm{ZnAl}-05$

With decreasing $\mathrm{Al}$ content in $\mathrm{LDH}$ structure to be $15 \mathrm{wt} \%$, the XRD pattern of $\mathrm{ZnAl}-15$ showed that the intensity of all reflections decreased without shifting of the $a, c$ parameters as shown in Fig. 1b. With further decreasing $\mathrm{Al}$ content in LDH structure, Fig. 1c shows overlap between the main peak of LDH $(0.76 \mathrm{~nm})$ and the main peak of hydrozincite phase. Although the growth of hydrozincite phase increased, the $a, c$ parameters of the LDH did not change. It means that $\mathrm{ZnAl}-05$ still has LDH structure. The low crystallinity of Zn-Al LDH, observed with reducing the content of aluminum, could be due to the growth of hydrozincite phase that caused distortion in the layered structure of LDH.

In order to identify the nature of the prepared structures, the FTIR spectra were measured for the prepared samples $\mathrm{ZnAl}-30, \mathrm{ZnAl}-15$ and $\mathrm{ZnAl}-05$. Figure 2 shows that they have similar structures. The broad absorption at $3467 \mathrm{~cm}^{-1}$ corresponded to the $\mathrm{OH}$ stretching mode of the nanolayered structures of $\mathrm{ZnAl}-30$. In the case of both $\mathrm{ZnAl}-15$ and $\mathrm{ZnAl}-05$, two shoulders overlapped with the $\mathrm{OH}$ band at 3570 and $3400 \mathrm{~cm}^{-1}$ indicating different kinds of $\mathrm{OH}$ groups. It confirmed the presence of hydrozincite phase besides the nanolayered structures of $\mathrm{Zn}-\mathrm{Al} \mathrm{LDH}$, agreeing with the results of XRD. The broadness of the $\mathrm{OH}$ band may be due to the existence of hydrogen bonds. Also, the $\mathrm{OH}$ stretching mode of interlayer water molecules and hydrogen bonded to interlayer carbonate anions were confirmed by a clear shoulder peak at around $3000 \mathrm{~cm}^{-1}$ [35]. The bending mode band of water molecules was observed at $1642 \mathrm{~cm}^{-1}$ [36]. Figure 2a shows two bands at 1430 and $1360 \mathrm{~cm}^{-1}$ for ZnAl-30. These bands are due to mode $v_{3}$ of interlayer carbonate species [37], while in the case of $\mathrm{ZnAl}-15$ and $\mathrm{ZnAl}-05$, these bands were recorded at 1503 and
$1360 \mathrm{~cm}^{-1}$, respectively. For free carbonate species, the vibration mode was recorded at $1450 \mathrm{~cm}^{-1}$. In the case of aragonite, it split into two bands at 1504 and $1492 \mathrm{~cm}^{-1}$ because of symmetry lowering. In the current case, the splitting was similar because of the restricted symmetry of carbonate in the interlayer space of LDH. The $v_{1}$ mode of carbonate was observed as weak band at $1081 \mathrm{~cm}^{-1}$ [38]. The sharp bands observed below $1000 \mathrm{~cm}^{-1}$ are due to the modes $v_{2}$ and $v_{4}$ of carbonate $[37,38]$. The insertion of cyanate anions $\left(\mathrm{NCO}^{-}\right)$into $\mathrm{Zn}-\mathrm{Al} \mathrm{LDHs}$ was confirmed by clear bands in the region of $2230-2105 \mathrm{~cm}^{-1}$ as shown in Fig. 2b [35]. The FTIR results concluded that the samples $\mathrm{ZnAl}-30, \mathrm{ZnAl}-15$, and $\mathrm{ZnAl}-05$ have LDH structures.

Thermal measurements were used in order to investigate the phase transformations of the nanolayered structures during the thermal treatment. The recorded thermogravimetric and differential scanning calorimetric (TG-DSC) curves showed that the degradation occurs through several stages with various mass rate losses, depending upon the nature of the interlayer anions. From the TG-DSC curves of $\mathrm{ZnAl}-30$, which has $30 \mathrm{wt} \% \mathrm{Al}$, the degradation process exhibited five mass losses. The first and second mass losses (11 wt $\%$ ) were detected at $50-170{ }^{\circ} \mathrm{C}$ followed by endothermic effect at $160^{\circ} \mathrm{C}$, due to the loss of physisorbed and interlayer water. The other three mass losses (17 wt \%) were observed at higher temperatures $170-305^{\circ} \mathrm{C}$ and followed by two endothermic peaks. These transitions are attributed to the removal of cyanate and carbonate anions in addition to the dehydroxylation of the LDH layers. Further heating produced a broad exothermic peak above $425{ }^{\circ} \mathrm{C}$. It was accompanied by a small mass loss of $3 \mathrm{wt} \%$. This exothermic peak may be due to the crystallization of the Aldoped zinc oxide. 


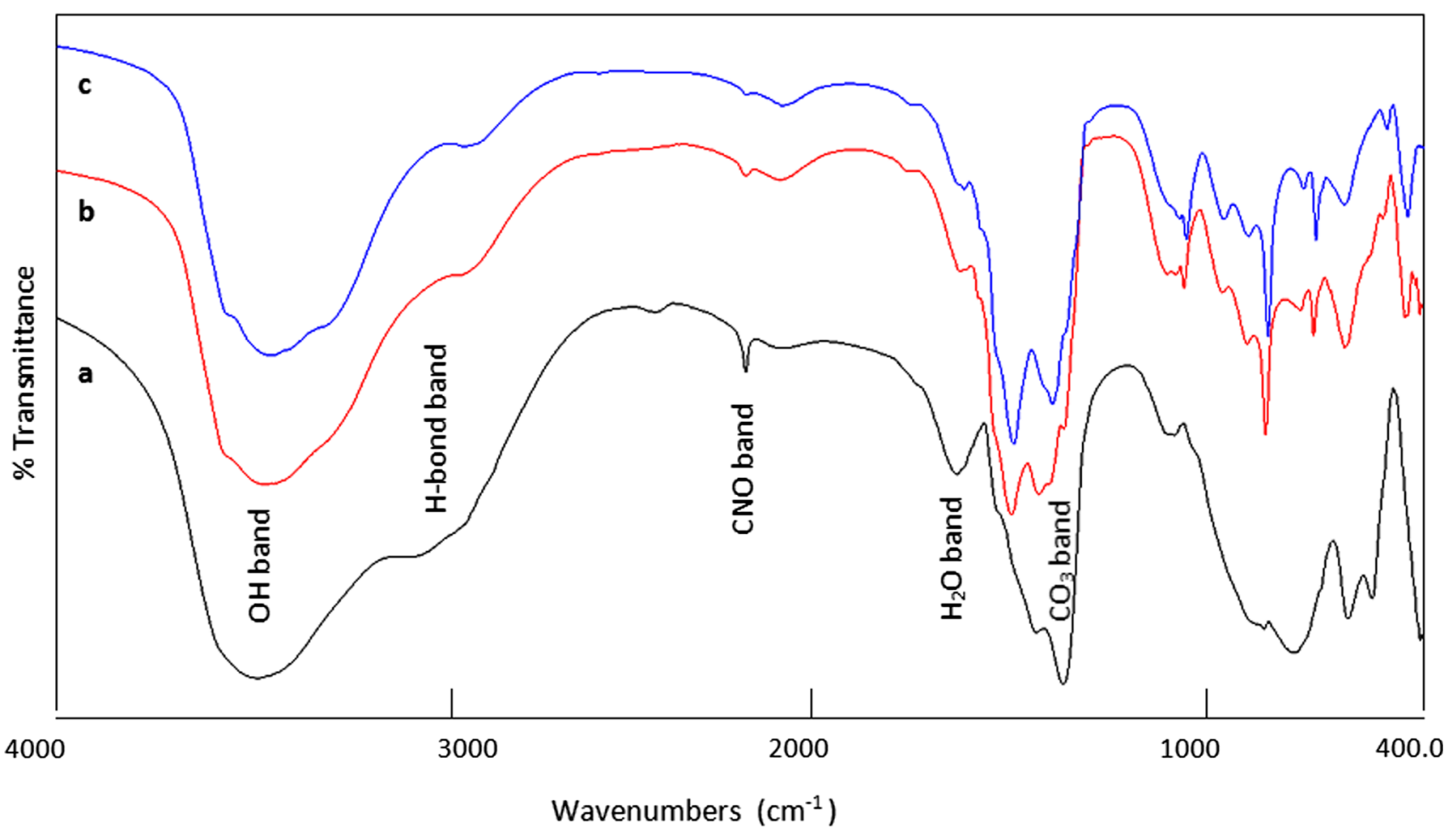

Fig. 2 FTIR spectra of: $a \mathrm{ZnAl}-30, b \mathrm{ZnAl}-15, c$ ZnAl-05

With decreasing the percentages of aluminum to be 15 and $5 \mathrm{wt} \%$, some differences in the thermal analyses of ZnAl-15 and $\mathrm{ZnAl}-05$ were noticeable as shown in Fig. 3b, c. The degradation occurred through four stages. Also, the mass loss corresponding to the interlayered water decreased to be less than 5 wt $\%$ for both $\mathrm{ZnAl}-15$ and $\mathrm{ZnAl}-05$, while the mass loss of the removal of carbonate anions increased to be $18-20 \mathrm{wt} \%$. These differences may be due to the presence of hydrozincite structure in addition to $\mathrm{Zn}-\mathrm{Al} \mathrm{LDH}$ in both $\mathrm{ZnAl}-15$ and ZnAl-05 agreeing with XRD results.

The nanolayered structures of the prepared samples were confirmed by transmission electron microscopy. It is known that usual morphology of layered double hydroxide (pyroaurite) is platelike morphology [39, 40]. A similar morphology is detected for ZnAl-30, ZnAl-15, and ZnAl-05. Figure 4a shows TEM image of ZnAl-30 indicating $100 \mathrm{~nm}$ for the thickness of the plates. However, at higher magnification, irregular plates were noticed because of aggregation of the platelets. Energy-dispersive X-ray spectrometry showed that zinc, aluminum, and oxygen were clearly recognized in the platelets as shown in Fig. 4b. The signals of copper and carbon were due to the grid of the TEM.

\subsection{Transformation of Nanolayers to Nanonets and Nanofibers}

XRD patterns of the products obtained by treatment of the nanolayered structures at high pressure and temperature are shown in Fig. 5. These XRD patterns exhibited new peaks at higher $2 \theta$ and the original peaks of the layered structures disappeared. All the diffraction lines obtained were identified as wurtzite (JCPDS No. 36-1451) ZnO crystal by matching and fitting with the standard entire diffraction pattern of zincite phase and zinc oxide (JCPDS No. 75576). In the case of $\mathrm{ZnAl}-30-\mathrm{TP}$, the characteristic peaks of zincite phase were broad and diffuse, possibly because of the presence of the amorphous structure of aluminum oxide inside the zincite phase. By doping of $\mathrm{ZnO}$ with lower concentrations of aluminum, 5 and 15\%, XRD patterns exhibited high crystallinity of the wurtzite hexagonal structure. However, the considerable broadened diffraction peaks indicated the nanoscale crystallinity of the $\mathrm{ZnO}$ particles with randomly oriented polycrystalline. Therefore, the crystalline size could be calculated based on the Debye-Scherer equation [25]:

$D=k \lambda /(\beta \cos \theta)$

where $k$ is constant (shape factor about 0.9 ), $\lambda$ is the wavelength of the X-ray used $\left(1.5418 \times 10^{-10} \mathrm{~m}\right), \beta$ is the FWHM of the diffraction line, and $\theta$ is the angle of the diffraction.

The mean crystallites sizes of the treated samples ZnAl30-TP, ZnAl-15-TP, and ZnAl-05-TP were estimated from XRD peaks width of the planes (100) (002) and (101) and are summarized in Table 1. 

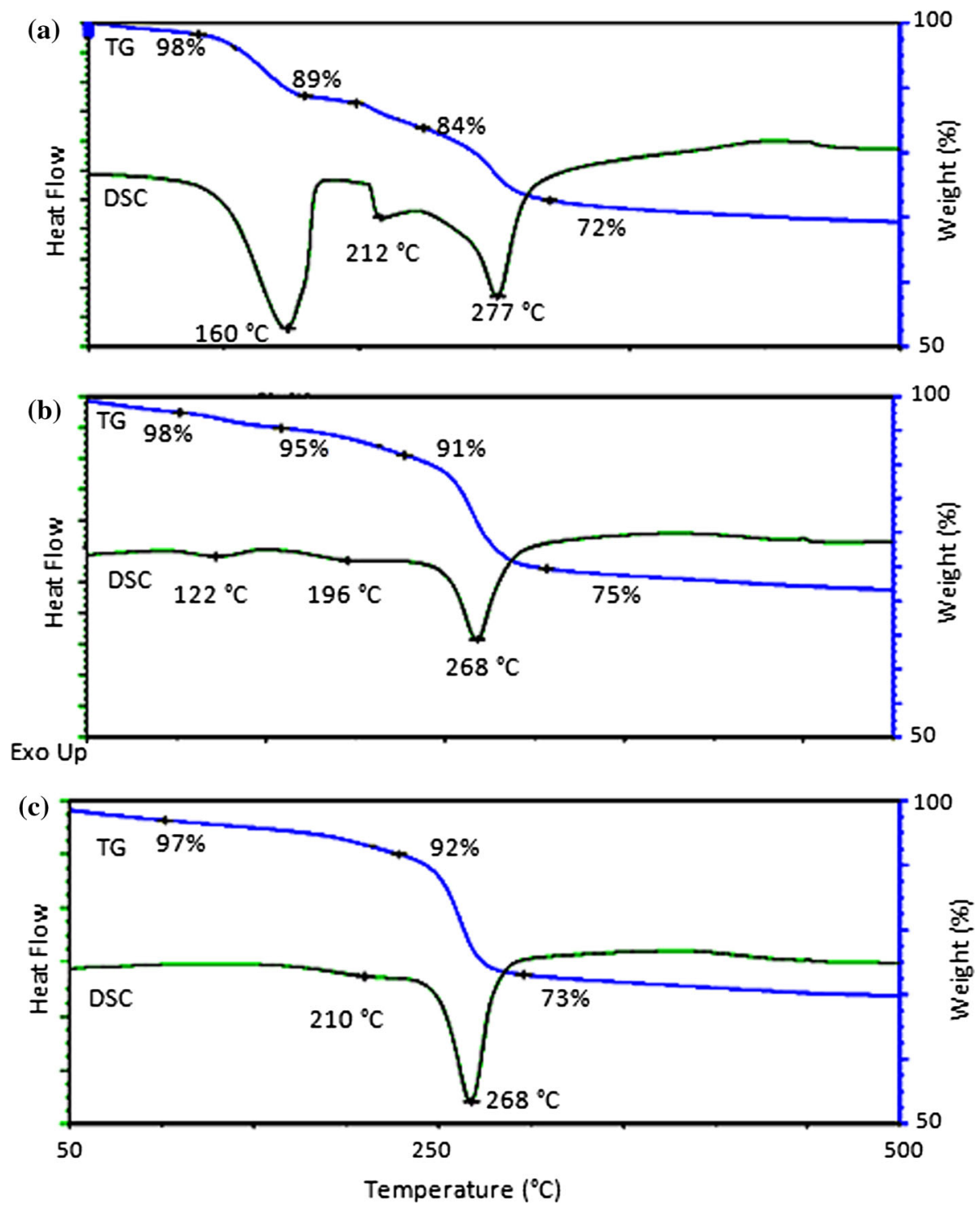

Fig. 3 Thermal analyses (TG and DSC) of: a ZnAl-30, b ZnAl-15, c ZnAl-05
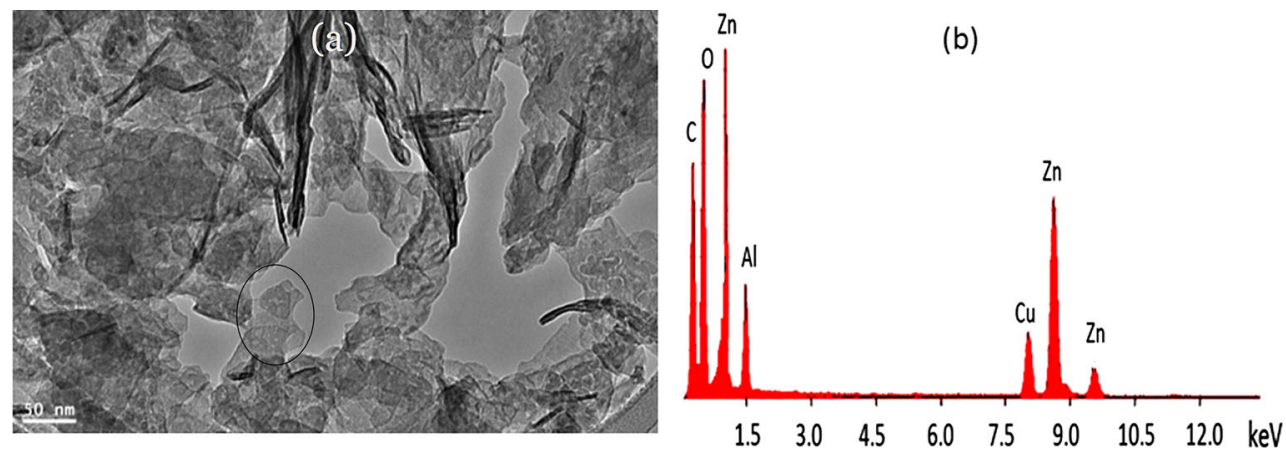

Fig. 4 TEM images a and EDX analysis b of ZnAl-30

The mean crystallites size of the particles of ZnAl-30TP was $6 \mathrm{~nm}$. Slightly higher values $(11$ and $16 \mathrm{~nm})$ were obtained for ZnAl-15-TP and ZnAl-05-TP, respectively.
These results mean that the nanolayered structures of $\mathrm{Zn}$ Al LDHs were transformed to the particles of zinc oxide doped with aluminum in the nanoscale. A clear relationship 


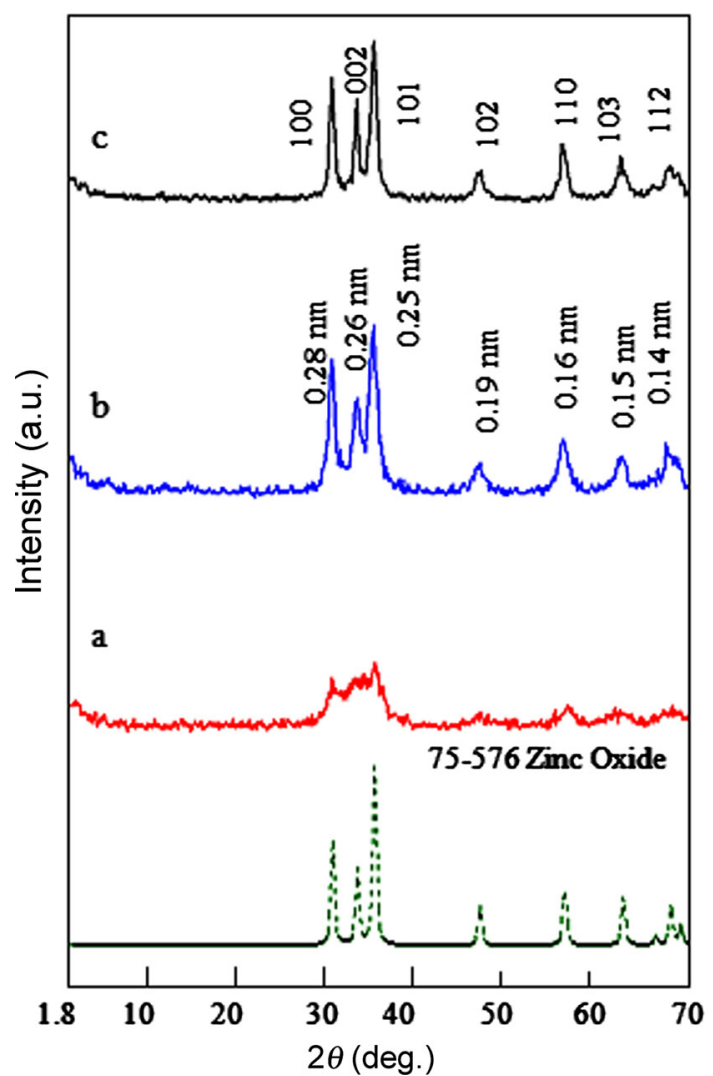

Fig. 5 XRD patterns of: $a \mathrm{ZnAl}-30-\mathrm{TP}, b$ ZnAl-15-TP, $c$ ZnAl-05-TP

Table 1 Average crystallite size calculated from X-ray patterns of the treated nanolayered structures

\begin{tabular}{lllll}
\hline Samples & $2 \theta$ (deg.) & Area & Cry. size $(\mathrm{nm})$ & Av. size $(\mathrm{nm})$ \\
\hline ZnAl-30-TP & 31.7 & 100 & 7.8 & 6 \\
& 34.4 & 291 & 3 & \\
& 36.2 & 164 & 6.4 & 11 \\
ZnAl-15-TP & 31.7 & 194 & 11.4 & \\
& 34.4 & 136 & 10.8 & 16 \\
& 36.2 & 305 & 9.6 & \\
ZnAl-05-TP & 31.7 & 192 & 16.2 & \\
& 34.4 & 140 & 16.2 & \\
& 36.2 & 317 & 14.5 & \\
\hline
\end{tabular}

was observed between the concentration of aluminum and the nanosize of zinc oxide, where the crystallite size of the doped zinc oxide increased with the reduction in the content of aluminum in its nanostructures.

Transformation of $\mathrm{Zn}-\mathrm{Al}$ nanolayered structures to nanoparticles was confirmed by transmission electron microscope. Figure 6 shows that the platelike structure of ZnAl-30-TP disappeared after the treatment at high pressure and temperature. Also, the nanoparticles were observed at $5 \mathrm{~nm}$. These nanoparticles were connected together in aggregates looking like shape of nanonets. In the case of ZnAl-15-TP, aggregates of the nanoparticles were also observed as shown in Fig. 7. However, the particles size became higher than $10 \mathrm{~nm}$. In addition to the nanoparticles, Fig. 7c shows some of the nanofibers. It means that nanoparticles and nanofiber started to separate from the nanonets structures with the reduction in aluminum content. Nanofibers became clearer with further reduction in aluminum content as shown in Fig. 8. Figure 8 shows the TEM images of $\mathrm{ZnAl}-05-\mathrm{TP}$, revealing the nanoparticles at $15 \mathrm{~nm}$ and nanofibers with diameter about $5 \mathrm{~nm}$.

The chemical composition of the ZnAl-30-TP, ZnAl-15$\mathrm{TP}$, and ZnAl-05-TP was analyzed by energy-dispersive $\mathrm{X}$-ray analysis (EDX) as shown in Figs. 6c, 7d, and 8e. The zinc, aluminum, and oxygen peaks were clearly shown. The EDX analysis and XRD results indicated that the aluminum was successfully immobilized onto the zinc oxide nanoparticles.

\subsection{Optical Properties}

The UV-Vis absorption spectra are believed to be a powerful tool to study the optical properties of the $\mathrm{Zn}-\mathrm{Al} \mathrm{LDHs}$ and their oxides and provide important information about their band gaps. In the case of $\mathrm{ZnAl}-30$, which has $15 \mathrm{wt} \%$ Al, Fig. 9a shows that no clear absorption band could be detected in the visible light region (400-800 nm). It means that $\mathrm{ZnAl}-30$ is inert with irradiation of visible light, while, in the UV region, a strong absorption peak was observed at $190 \mathrm{~nm}$ that could be attributed to the electronic transition from oxygen $2 p$ to metal ns or np levels $(n=4)$ [41]. With decreasing the percentage of aluminum to be 15 and $5 \mathrm{wt} \%$, the samples of $\mathrm{ZnAl}-15$ and $\mathrm{ZnAl}-05$ exhibited similar absorption behavior as shown in Fig. 9b, c.

The main absorption, which matched to an electronic excitation from the valence band to the conduction band, could be used to calculate the energy band gap $\left(E_{\mathrm{g}}\right)$. The link between the incident photon energy $(h v)$ and the absorption coefficient $(\alpha)$ can be written as [42]:

$(\alpha h v)^{m}=A\left(h v-E_{\mathrm{g}}\right)$

where $A$ is constant and $m$ is an index that describes the optical absorption process. The $m$ values are $1 / 2$ and 2 for allowed indirect and allowed direct transitions, respectively.

The electronic transition of $\mathrm{Zn}-\mathrm{Al} \mathrm{LDH}$ is a direct process from the oxygen $2 p$ to the metal ns or np levels ( $n=4$ for $\mathrm{Zn}$ and $n=3$ for $\mathrm{Al}$ ) [41]. Thus, by plotting $(\alpha h v)^{2}$ and $(h v)$, the band gap of Zn-Al LDH could be determined through extending the straight line to the $(h v)$ axis to get the optical band gap of the samples at $(\alpha h v)^{2}$ of 0 as shown in Fig. 9d, e, f. 


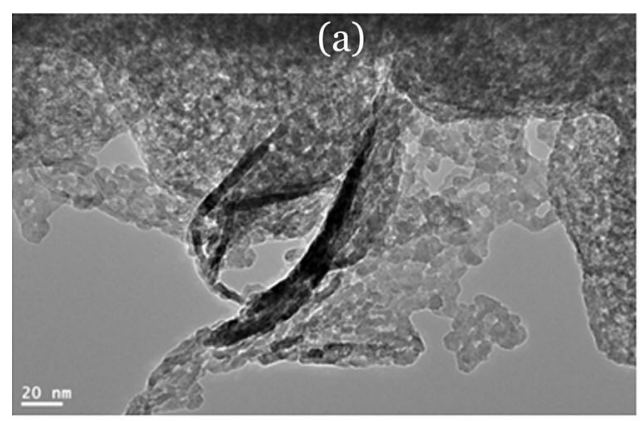

Zn

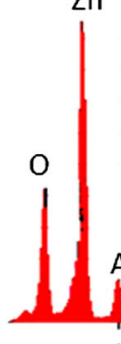

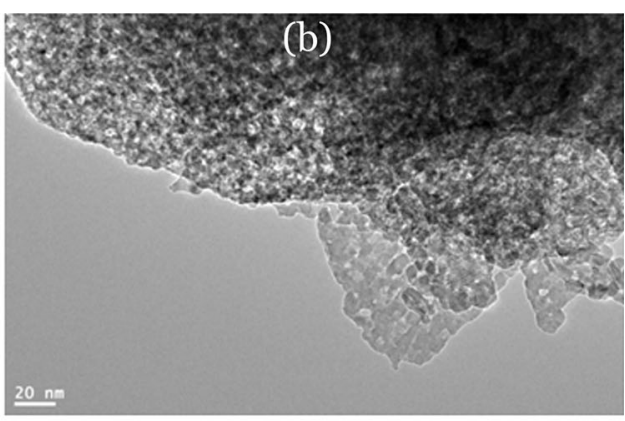

(c)

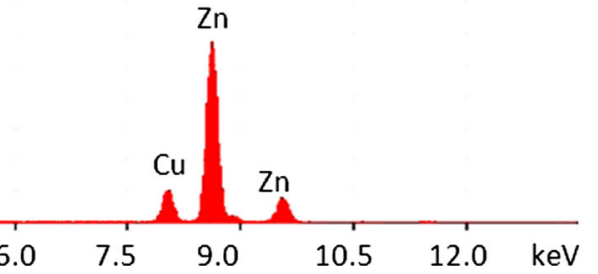

Fig. 6 TEM images and EDX analysis of ZnAl-30-TP
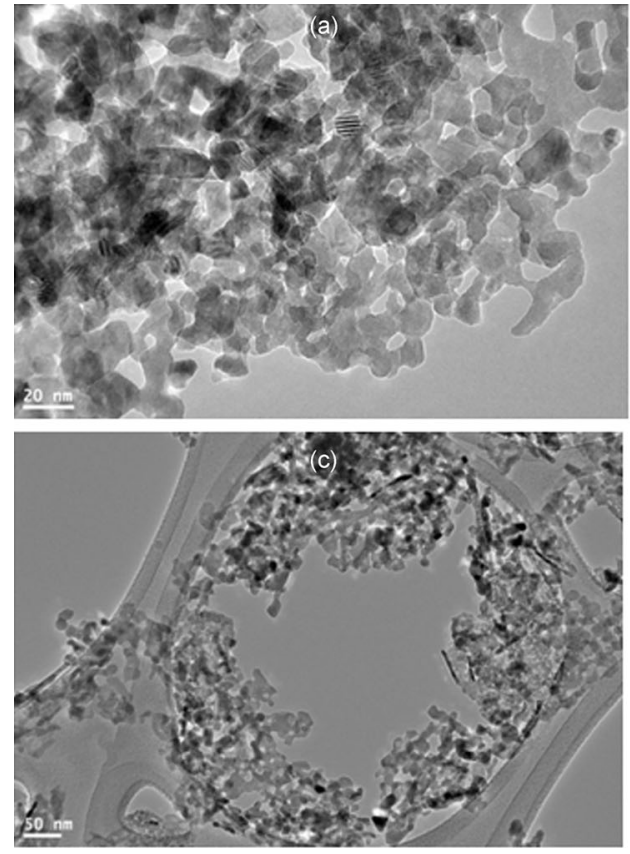

Fig. 7 TEM images and EDX analysis of ZnAl-15-TP

The band gap $\left(E_{\mathrm{g}}\right)$ values of $\mathrm{Zn}-\mathrm{Al} \mathrm{LDHs}$ at room temperature were in the range of 5.7-5.6 eV as shown in Fig. 9d-f. It was quite different from those of $\mathrm{Al}_{2} \mathrm{O}_{3}$ $\left(E_{\mathrm{g}}=3.6 \mathrm{eV}\right)$ and $\mathrm{ZnO}\left(E_{\mathrm{g}}=3.3 \mathrm{eV}\right)$. The band gap of the LDH structure could be ascribed to the presence of carbonate in the confined state inside the interlayer region.

By transforming the nanolayered structures of $\mathrm{Zn}-\mathrm{Al}$ LDHs to different morphologies of the nanoparticles and nanofibers, the absorbance spectra were shifted to visible
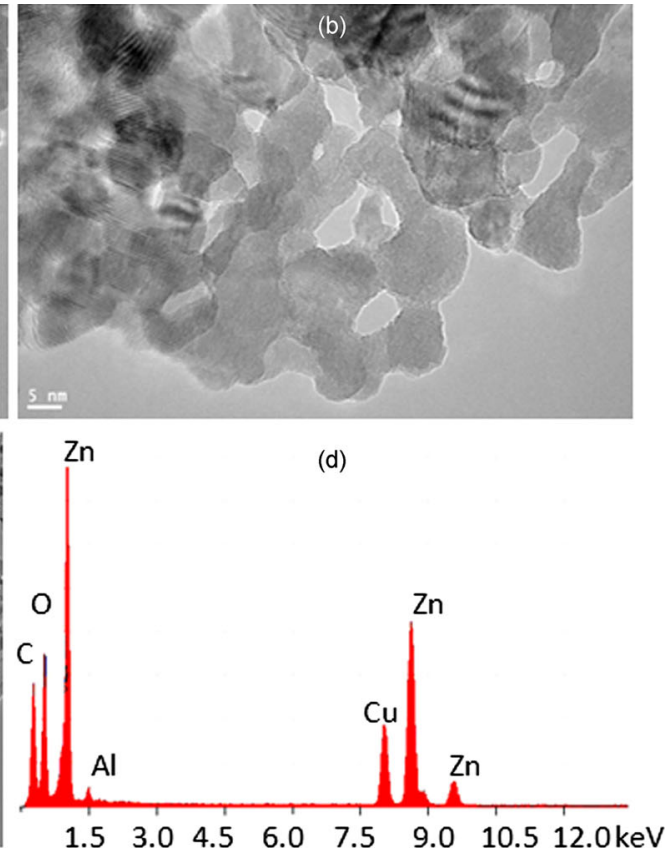

region and became wider as shown in Fig. 10. Figure 10a reveals the absorbance spectrum of $\mathrm{ZnAl}-30-\mathrm{TP}$ in the wavelength range of $200-380 \mathrm{~nm}$. The broad absorbance peak was due to the fundamental band-to-band electron excitations that related to the energy band gap of the sample [41]. The band gap $\left(E_{\mathrm{g}}\right)$ value of $\mathrm{ZnAl}-30$-TP was $3.25 \mathrm{eV}$ as shown in Fig. 10f. It was different from that of $\mathrm{Al}_{2} \mathrm{O}_{3}\left(E_{\mathrm{g}}=3.6 \mathrm{eV}\right)$ and a little lower than that of $\mathrm{ZnO}$ $\left(E_{\mathrm{g}}=3.3 \mathrm{eV}\right)$. Compared to the band gap of pure $\mathrm{ZnO}$, 

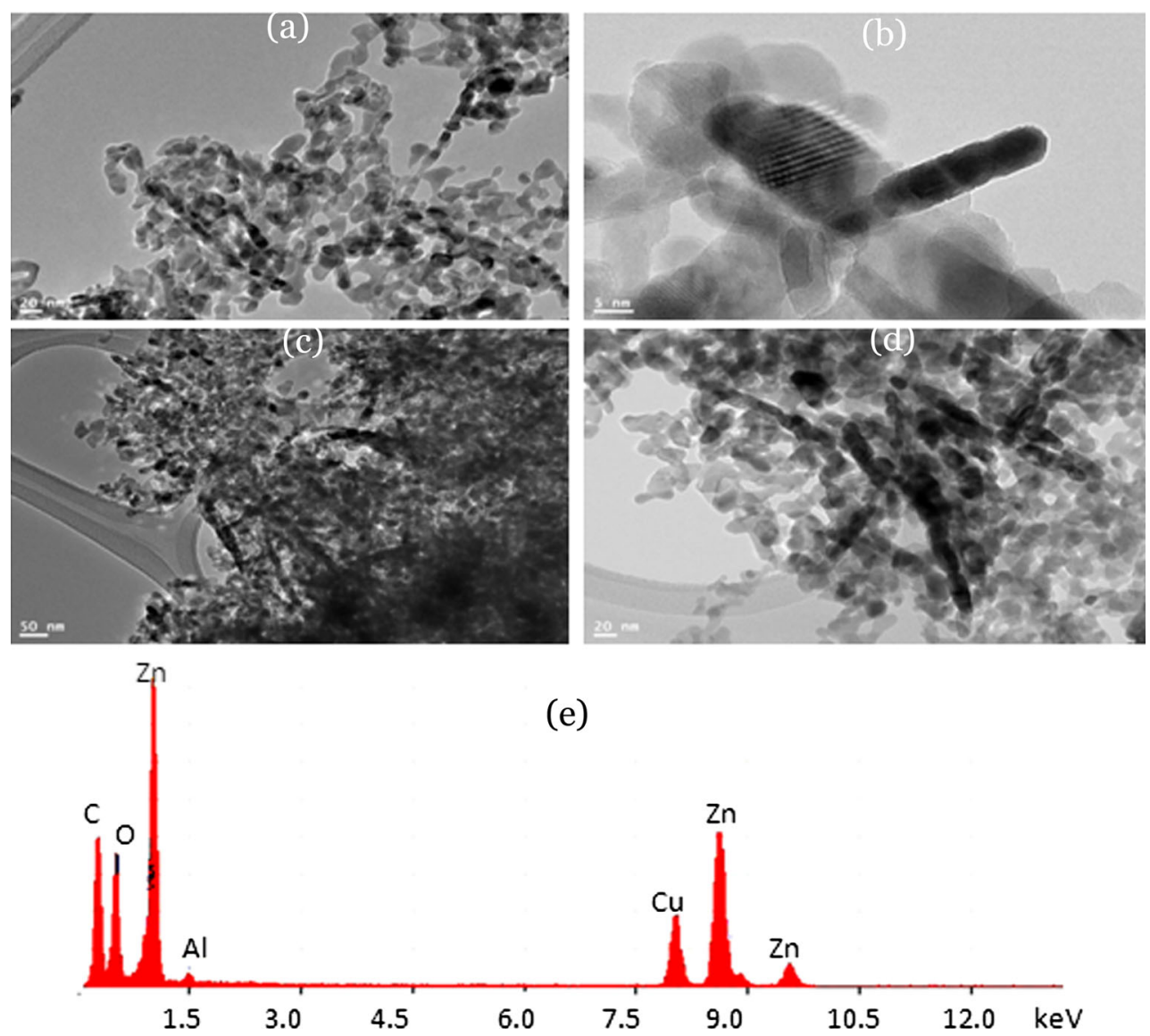

Fig. 8 TEM images and EDX analysis of ZnAl-05-TP
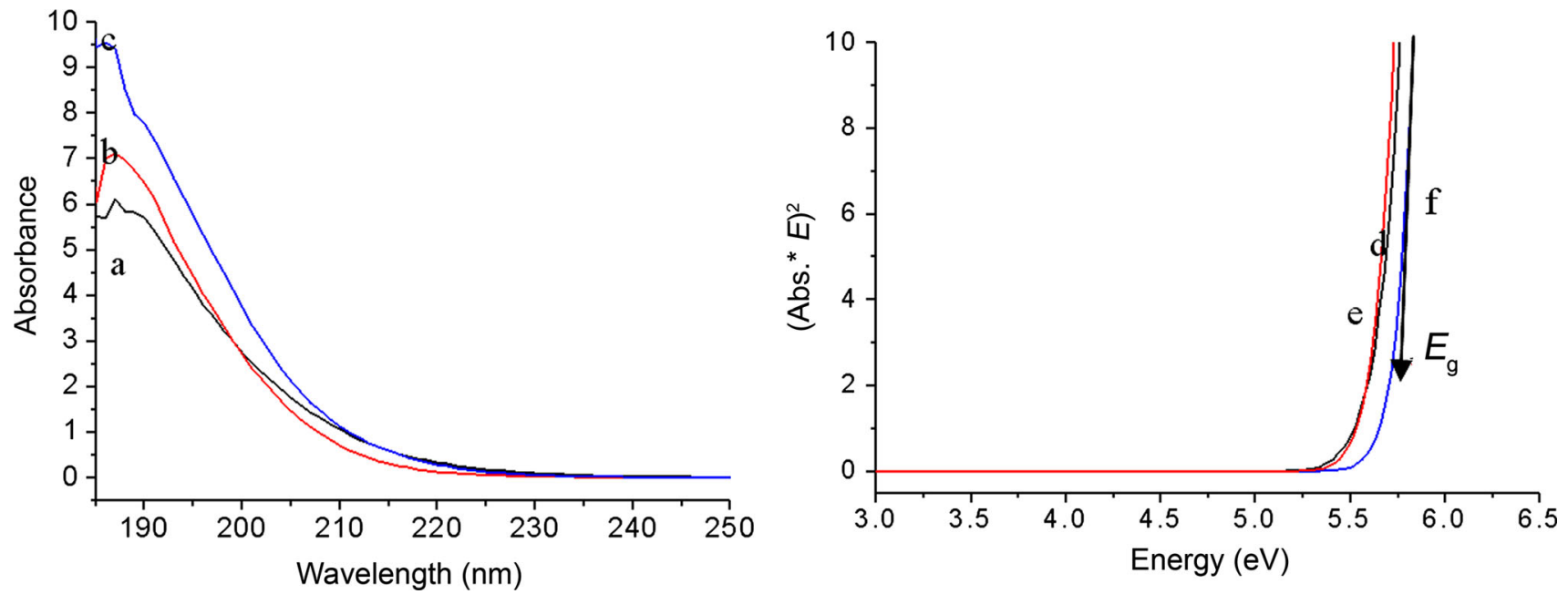

Fig. 9 UV-Vis spectra and band gaps of: $a, f \mathrm{ZnAl}-30, b, d \mathrm{ZnAl}-15, c$, $e$ ZnAl-05

narrowing of band gap of $\mathrm{ZnAl}-30-\mathrm{TP}$ happened after the doping of $\mathrm{ZnO}$ with $30 \mathrm{wt} \%$ aluminum. In order to evaluate the change in the band gap energy with changing $\mathrm{Al}$ concentrations, the relation $(\alpha h v)^{2}$ versus $(h v)$ was studied for the other two samples ZnAl-15-TP and ZnAl-05-TP. Figure $10 \mathrm{~d}$, e shows that the values of $E_{\mathrm{g}}$ have been found to be 3.11 and $3.06 \mathrm{eV}$ for 15 and $5 \mathrm{wt} \% \mathrm{Al}$ contents, respectively. According to these results, the doping of $\mathrm{ZnO}$ with aluminum caused narrowing of the band gap from 3.3 to $3.06 \mathrm{eV}$.

The observed band gap narrowing could be explained as follows. Physical properties of semiconductors are linked 

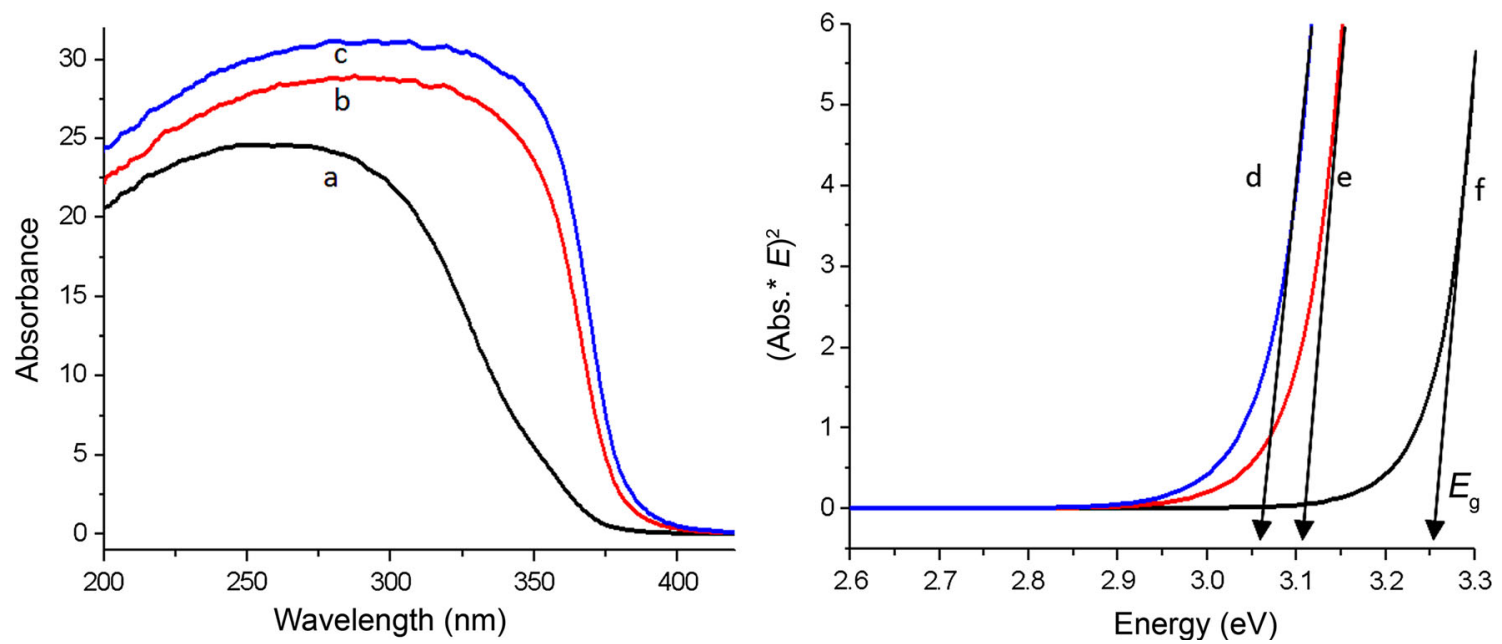

Fig. $10 \mathrm{UV-Vis} \mathrm{spectra} \mathrm{and} \mathrm{band} \mathrm{gaps} \mathrm{of:} a, f \mathrm{ZnAl}-30-\mathrm{TP}, b, e \mathrm{ZnAl}-15-\mathrm{TP}, c, d \mathrm{ZnAl}-05-\mathrm{TP}$

to their band gap energy that can be significantly changed (increased or decreased) by doping. The extent of the shift depended on two competing impacts. The first impact belonged to many body effects on the conduction and valence bands. It led to a band gap narrowing. This shrinkage was counteracted by the second impact due to the Burstein-Moss effect. This effect caused a band gap widening (blue shift) because of the blocking of lowest states in the conduction band. On the other hand, for higher donor density, band gap narrowing became significant because of many body effects, such as exchange energy due to electron-electron and electron-impurity interactions [43]. These effects also led to a narrowing of the band gap (red shift). In this case, the total measured optical band gap, $E_{\mathrm{g}}$, equaled the net result of blue and red shifts. Wolf [43] reported that the band gap had redshift in the heavily doped n-type semiconductors. Accordingly, our results could be interpreted in light of the above considering items. By doping $\mathrm{ZnO}$ with the high and low concentrations of $\mathrm{Al}$ (30, 15 and $5 \mathrm{wt} \%)$, the reduction in the blueshift occurred and the redshift raised. Therefore, the net result of both shifts led to a reduction in the band gap energy for the samples ZnAl-30-TP, ZnAl-15-TP ZnAl-05-TP and became more effective for their photocatalytic activities.

\subsection{Photocatalytic Degradation of Acid Green Dyes}

In order to determine the effective morphology of the Aldoped zinc oxides on their photocatalytic activities toward the colored pollutants, the photocatalytic degradation of AG1 was investigated by irradiating the aqueous solution of AG1 with the UV light in the presence of the nanolayers, nanofibers, or nanonets of the $\mathrm{Al}$-doped $\mathrm{ZnO}$ and measuring the absorbance of the liquid portion after the irradiation of UV for certain hours. The decrease in the absorption of AG1 at $\lambda_{\max }$ of $714 \mathrm{~nm}$ indicated the degradation of the main structure of the pollutant, while the degradation of the naphthyl rings in AG1 could be followed from the absorption peaks at 320,283 , and $232 \mathrm{~nm}$ as shown in Figs. 11 and 12.

Blank experiments were carried out without photocatalyst. AG1 was stable toward the light irradiation. The photocatalytic degradation of AG1 was investigated as a function of the UV light irradiation time in the presence of the photocatalyst. When AG1 solution was mixed with the used samples for $1 \mathrm{~h}$ in the dark, minor change was observed. For reference, it was used as 0 -h irradiation. When the aqueous solution of AG1 containing the photocatalyst was irradiated with the UV light, the photocatalytic degradation of AG1 was observed. The obtained results are illustrated in Figs. 11 and 12. The photocatalytic degradation of AG1 under UV light in the presence of the ZnAl30 nanolayers increased with the increase in irradiation time. At $4.2 \mathrm{~h}$ of irradiation time, there were nearly complete decolorization and degradation.

In the case of both $\mathrm{ZnAl}-15$ and $\mathrm{ZnAl}-05$, the photocatalytic degradation of AG1 was approximately similar to that of $\mathrm{ZnAl}-30$. Complete decolorization and mineralization of AG1 occurred in the nanolayers of $\mathrm{ZnAl}-15$ and ZnAl-05 within $4.3-4.7 \mathrm{~h}$ as shown in Fig. 11. It means that the decolorization and the photocatalytic degradation of AG1 for the nanolayers did not depend on the percentage of aluminum, but it may depend on the morphology, because the resemblance among their nanolayered structures resulted in similarity among the photocatalytic results of $\mathrm{ZnAl}-30, \mathrm{ZnAl}-15$ and $\mathrm{ZnAl}-05$. The little deviation among their results may be due to the formation of nonlayered structure of zinc hydroxycarbonate with the reduction in the percentage of aluminum. 

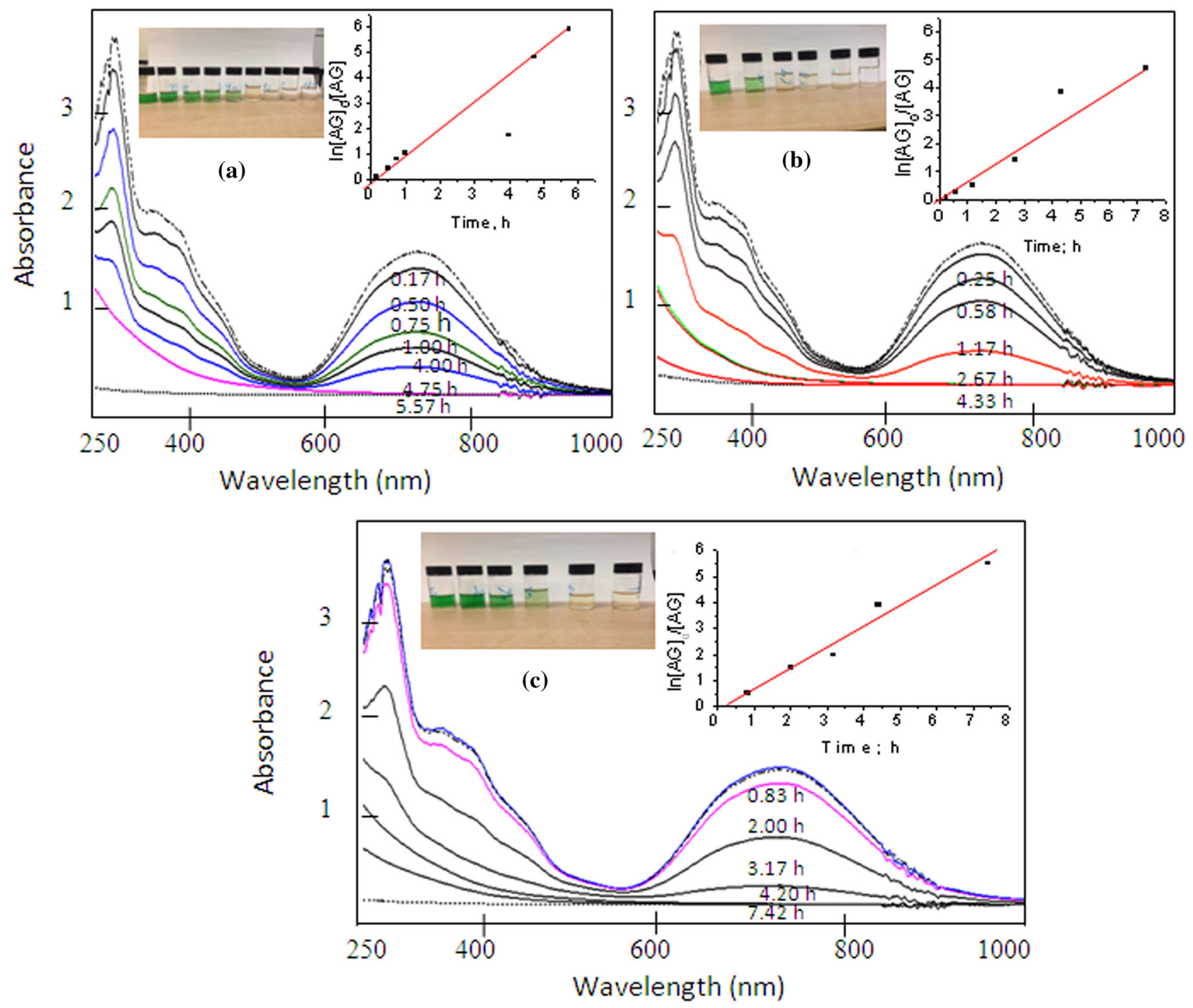

Fig. 11 Absorbance spectra of AG1 with different irradiation times in UV light in the presence of a ZnAl-05 LDH, b ZnAl-15 LDH, $\mathbf{c}$ ZnAl-30 LDH (inset-typical kinetics obtained for the mineralization of AG1)

By transforming the nanolayered structures to the nanonets and nanofibers, the decolorization and the photocatalytic degradation of AG1 became sensitive to the percentage of the dopant (aluminum) inside the structure of zinc oxides in addition to the nanosize of their particles. In the case of the nanofibers of ZnAl-05-TP, the complete decolorization and the photocatalytic degradation of AG1 were achieved at $2.7 \mathrm{~h}$. By using the ZnAl-15-TP nanoparticles, the time of the complete decolorization and the photocatalytic degradation of AG1 decreased to be $1.9 \mathrm{~h}$. By using the nanonets of $\mathrm{ZnAl}-30-\mathrm{TP}$, the complete decolorization and the photodegradation of AG1 were achieved at shorter time $1.3 \mathrm{~h}$. It can be concluded that the nanonets of $\mathrm{Al}$-doped $\mathrm{ZnO}$, which has the smallest nanosize, caused a complete removal for the AG1 pollutant at the shortest time. It means that the nanonets morphology of the doped zinc oxide particles was effective for the photocatalytic degradation process.

\section{Discussion}

Exposure of aqueous solutions of AG1 to direct UV light in the presence of the nanolayers, the nanofibers or the nanonets of the Al-doped $\mathrm{ZnO}$ caused decolorization of AG1 at different times. Figure 12 shows that the nanonets of the Al-doped $\mathrm{ZnO}$ caused a complete decolorization for AG1 at shorter time than that of the other morphologies. The complete degradation of the dye AG1 was verified by the disappearance of the absorbance band at $714 \mathrm{~nm}$ as shown 

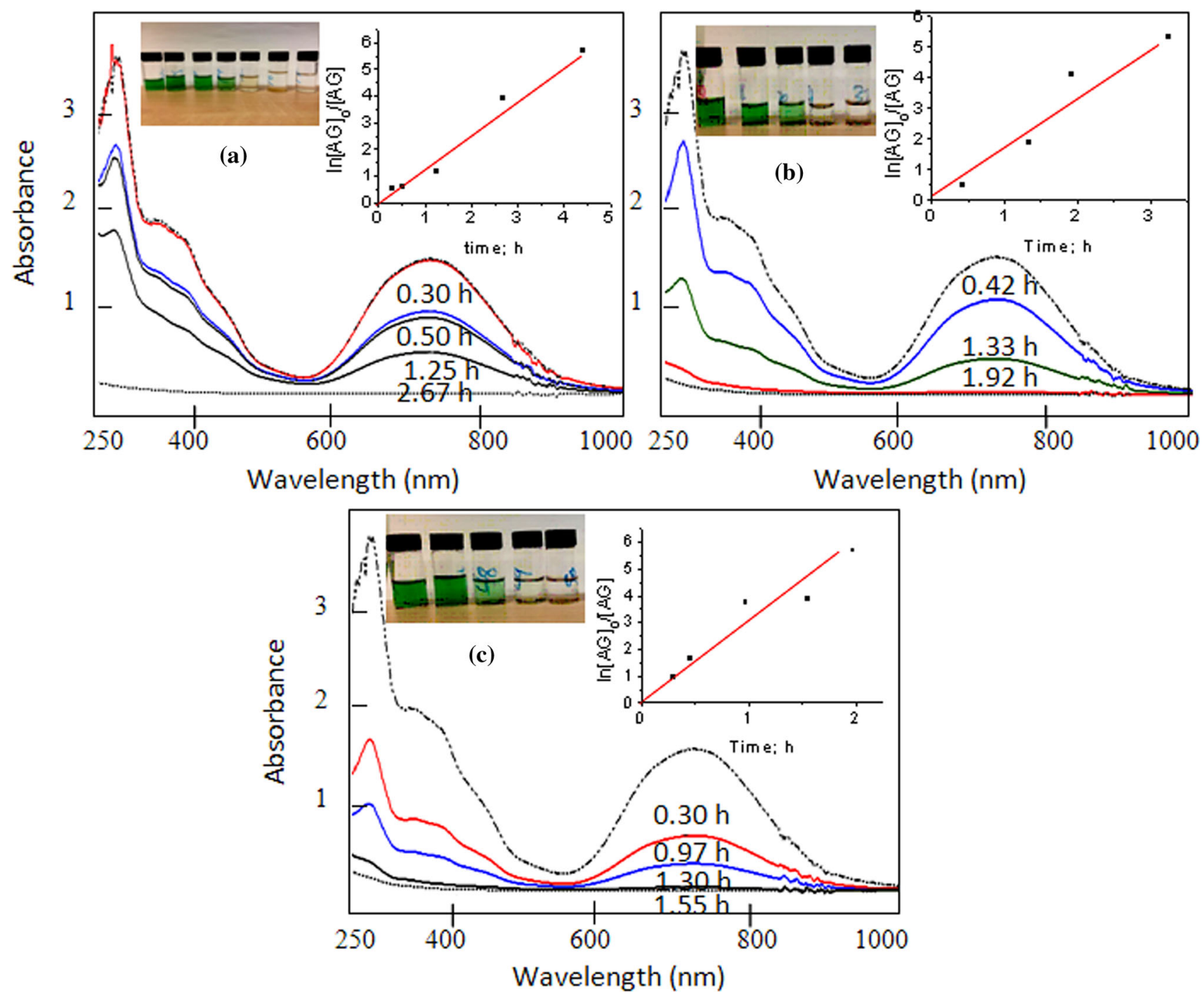

Fig. 12 Absorbance spectra of AG1 with different irradiation times in UV light in the presence of a ZnAl-05-TP, b ZnAl-15-TP, c ZnAl-30-TP (inset-typical kinetics obtained for the mineralization of AG1)

in Fig. 12. Also, it was confirmed by the disappearance of the bands of the intermediate organic phenyl groups at 320 , 283, and $232 \mathrm{~nm}$.

The theoretical basis for photocatalytic activity of the doped $\mathrm{ZnO}$ particles is due to their high oxidizing power when being exposed with photons of energy equal to, or higher than, their band gap energy as shown in Eqs. $(1,2)$. The photogenerated electrons could convert $\mathrm{O}_{2}$ to superoxide radical anion $\mathrm{O}_{2}$. The photogenerated holes react with the hydrocarbon chain of pollutant or $\mathrm{OH}\left(\right.$ or $\left.\mathrm{H}_{2} \mathrm{O}\right)$ to create the highly oxidizing $\mathrm{OH}$ radicals as shown in the following equations:

$$
\begin{aligned}
& \mathrm{Zn}-\mathrm{Al}-\mathrm{O} \stackrel{\mathrm{UV} \text { light }}{\longrightarrow} \mathrm{h}^{+}\left(\mathrm{V}_{\mathrm{b}}\right)+\mathrm{e}^{-}\left(\mathrm{C}_{\mathrm{b}}\right) \\
& \mathrm{H}_{2} \mathrm{O}+\mathrm{h}^{+} \rightarrow \mathrm{OH}+\mathrm{H}^{+}
\end{aligned}
$$

In the presence of the acid green dyes (AG1):

$$
\begin{aligned}
\mathrm{AG}^{*}-\mathrm{Zn}-\mathrm{Al}-\mathrm{O} \rightarrow & \mathrm{AG}^{+} \text {intermediates }+\mathrm{Zn}-\mathrm{Al}-\mathrm{O} \\
& +\mathrm{e}^{-}\left(\mathrm{C}_{\mathrm{b}}\right)
\end{aligned}
$$

$\mathrm{e}^{-}\left(\mathrm{C}_{\mathrm{b}}\right)+\mathrm{O}_{2} \rightarrow \mathrm{O}_{2}^{-}$

$\mathrm{AG}^{+}$intermediates $+\mathrm{O}_{2}^{-} \rightarrow$ Degradation products

In this study, the improvement of the photocatalytic activity of $\mathrm{ZnO}$, doped with $\mathrm{Al}$, could be explained according to three factors. The first factor is the small nanosizes of the doped zinc oxide particles and their effect on the band gap. The second one is the morphology of the doped zinc oxide that could make trapping and confinement for pollutants and ease separation between the electrons and holes evolved from the excitation of photocatalyst. The third and the main factor is the transformation of nanolayers to nanonets and nanofibers that 
were capable of achieving the other two factors. The three factors improved the photocatalytic degradation of the acid green dyes through accelerating Eq. (3) of the degradation mechanism.

The nanonets of the Al-doped $\mathrm{ZnO}$, which showed the highest photocatalytic activity, were produced from the thermal decomposition of the nanolayered structures of the $\mathrm{LDH}$ containing $30 \mathrm{wt} \% \mathrm{Al}$. These nanonets are composed of small nanoparticles $(5 \mathrm{~nm})$ connecting together by nanofibers. These nanostructures were very effective for the degradation process of the pollutants because of the easy transportation and separation of the electrons and holes evolved from the excitation of photocatalyst. Also, these structures facilitated the trapping and confinement of the molecules of AG1 pollutants.

By decreasing the percentage of aluminum to be 15 and $5 \mathrm{wt} \%$, the layered structure of LDH started to fail and other phase started to grow. Accordingly, the size of the nanoparticles of the $\mathrm{Al}$-doped $\mathrm{ZnO}$, produced from the treatment of these nanolayered structures of LDH, increased to be 10 and $15 \mathrm{~nm}$, respectively. Therefore, the nanonet structures started to collapse producing the nanoparticles and nanofibers. Also, the photocatalytic efficiencies of ZnAl-15-TP and ZnAl-05-TP were lower than that of ZnAl-30-TP.

The low activity of the nanolayered structures of the $\mathrm{Zn}-\mathrm{Al} \mathrm{LDHs}$ containing carbonate anions may be due to the scavenging or consuming of the $\mathrm{OH}$ radicals through reacting with carbonate anions [34]. Also, the intercalation of pollutants inside the internal surface of the nanolayered structures is not easy. It led to inhibition of photocatalytic degradation of the green dyes.

By comparing these results with our results that were previously reported for the nanospheres of the Al-doped $\mathrm{ZnO}$ [25], the nanonets of the Al-doped $\mathrm{ZnO}$ showed higher photocatalytic activities. The nanospheres of the Aldoped $\mathrm{ZnO}$ caused complete degradation for AG1 at $6 \mathrm{~h}$, while the complete degradation of AG1 was achieved in $1.3 \mathrm{~h}$ for the nanonets of the $\mathrm{Al}$-doped $\mathrm{ZnO}$. It means that the morphology of the photocatalyst has vital role in the photocatalytic degradation process.

In order to confirm this speculation, the kinetics of photocatalytic decolorization and degradation of AG1 were studied for the nanolayers, nanonets, and the nanofibers by the following equation:

$\ln \left(C_{\mathrm{o}} / C\right)=k t$

where $C_{\mathrm{o}}$ is the absorbance at $t=0, C$ is the absorbance at different times, and $k$ is the rate constant. The kinetic studies of AG1 for the Al-doped $\mathrm{ZnO}$ nanolayers, nanonets, and nanofibers in UV light were represented in the plots of $\ln \left(C_{\mathrm{o}} / C\right)$ versus irradiation time as shown in Figs. 11, 12 (inset).
From Figs. 11 and 12 (inset), it could be inferred that the decolorization and the photodegradation of AG1 by UV light employing the Al-doped $\mathrm{ZnO}$ nanolayers as photocatalysts exhibited pseudo-first-order kinetic with rate constant $0.6-1 \mathrm{~h}^{-1}$ agreeing with the results of photocatalytic degradation of methylene blue dye under UV light [34]. By transforming the nanolayers to nanonets, the rate constant of the $\mathrm{ZnAl}-30$-TP increased to become 4.5 times higher than that of the $\mathrm{ZnAl}-30 \mathrm{LDH}$. In the case of $\mathrm{ZnAl}-$ 15-TP and ZnAl-05-TP, they are 3 and 1.5 times higher than their nanolayers, respectively.

The kinetic study indicated that the transformation of the nanolayers to nanonets and nanofibers increased the reaction rate of photocatalytic degradation of dyes. Finally, it confirmed that the morphology of the photocatalyst is an important factor for photocatalytic degradation processes of dyes.

\section{Conclusions}

The present study has a dual aim for developing method to control the morphology of the produced oxides from the decomposition of LDH structures and studying the effect of the morphology of the Al-doped zinc oxides on their photocatalytic degradation of the colored pollutants. In this way, nanolayered structures of zinc oxide combined with different concentrations of aluminum have been prepared and transformed to nanonets and nanofibers. The obtained band gap energy of the prepared nanomaterials was investigated according to their morphologies. According to the morphology which produced from the decomposition of nanolayered structures, the band gap energy for the nanofibers and the nanonets of the $\mathrm{Al}$-doped $\mathrm{ZnO}$ was reduced and became more effective for photocatalytic degradation of dyes.

This behavior was proven by the mineralization and the decolorization for acid green dyes at shorter time $1.3 \mathrm{~h}$ in the case of using the nanonets of the $\mathrm{Al}$-doped $\mathrm{ZnO}$. These results were confirmed from the kinetic study of the photocatalytic degradation of dyes in the presence of the different morphologies of the Al-doped $\mathrm{ZnO}$. Finally, it can be concluded that the morphology of the photocatalyst is an important factor for photocatalytic degradation processes of dyes.

Acknowledgements The authors thank the Deanship of Scientific Research in King Faisal University (Saudi Arabia) for funding and providing the facilities required for this research as a part of Annual Research Grants Program (No. 170047). 


\section{References}

[1] K.E. Trenberth, A. Dai, G. van der Schrier, P.D. Jones, J. Barichivich, K.R. Briffa, Nat. Clim. Change 4, 17 (2014)

[2] S. Ayrault, P. Le Pape, O. Evrard, C.R. Priadi, C. Quantin, P. Bonté, M. Roy-Barman, Environ. Sci. Pollut. Res. 21, 413 (2014)

[3] X. Miao, Y. Tang, C.W. Wong, Nature 518, 483 (2015)

[4] X. Yuan, L. Zhang, J. Li, C. Wang, J. Ji, Catena 119, 52 (2014)

[5] V. Belenguer, F. Martinez-Capel, A. Masiá, Y. Picó, J. Hazard. Mater. 265, 271 (2014)

[6] M. Fujita, Y. Ide, D. Sato, P.S. Kench, Y. Kuwahara, H. Yokoki, Chemosphere 95, 628 (2014)

[7] J. Sherman, D. Gaal, Materials management and pollution prevention, in The Role of Anesthesiology in Global Health (Springer, Berlin, 2015)

[8] S. Wang, J. Yun, B. Luo, T. Butburee, P. Peerakiatkhajohn, S. Thaweesak, M. Xiao, L. Wang, J. Mater. Sci. Technol. 33, 1 (2017)

[9] B.D. Mert, B. Yazıc1, Acta Metall. Sin. (Engl. Lett.) 28, 858 (2015)

[10] S. Banerjee, S.C. Pillai, P. Falaras, K.E. O'shea, J.A. Byrne, D.D. Dionysiou, J. Phys. Chem. Lett. 5, 2543 (2014)

[11] N. Daneshvar, D. Salari, A.R. Khataee, J. Photochem. Photobiol. A Chem. 162, 317 (2004)

[12] M.J. Chithra, M. Sathya, K. Pushpanathan, Acta Metall. Sin. (Engl. Lett.) 28, 394 (2015)

[13] H.S. Al-Salman, M.J. Abdullah, Acta Metall. Sin. (Engl. Lett.) 28, 230 (2015)

[14] Q. Wang, C. Tang, C. Jiang, D. Du, F. Wang, J. Song, Acta Metall. Sin. (Engl. Lett.) 29, 237 (2016)

[15] W. Zhou, X. Li, L. Qin, S. Kang, J. Mater. Sci. Technol. 33, 47 (2017)

[16] C. Liu, H. Xu, L. Wang, X. Qin, Acta Metall. Sin. (Engl. Lett.) 30, 36 (2017)

[17] X. Bai, L. Wang, R. Zong, Y. Lv, Y. Sun, Y. Zhu, Langmuir 29, 3097 (2013)

[18] Y. Leung, X. Chen, A. Ng, M. Guo, F. Liu, A. Djurisic, W. Chan, X. Shi, M. Van Hove, Appl. Surf. Sci. 271, 202 (2013)

[19] S. Lee, T. Lim, J. Roh, C. Ju, S. Park, S. Hong, S. Lee, G. Lee, in Proceedings of the 4th International Congress of Chemistry and Environment, Ubon Ratchathani, 2009
[20] H. Chen, L. Zhao, X. He, G. Wang, X. Wang, W. Fang, X. Du, Acta Metall. Sin. (Engl. Lett.) 30, 104 (2017)

[21] J.B. Zhong, J.Z. Li, X.Y. He, J. Zeng, Y. Lu, W. Hu, K. Lin, Curr. Appl. Phys. 12, 998 (2012)

[22] J. Sin, S. Lam, K. Lee, A. Mohamed, Ceram. Int. 39, 5833 (2013)

[23] M. Ahmad, E. Ahmed, Y. Zhang, N.R. Khalid, J. Xu, M. Ullah, Z. Hong, Curr. Appl. Phys. 13, 697 (2013)

[24] L. Huang, N. Ren, B. Li, M. Zhou, Acta Metall. Sin. (Engl. Lett.) 28, 281 (2015)

[25] O. Saber, T. Ali, A.A. Aljaafari, Water. Air Soil Poll. 223, 4615 (2012)

[26] X. Zhang, J. Bai, H. Zhang, Appl. Clay Sci. 119, 410 (2016)

[27] O. Saber, Curr. Nanosci. 7, 134 (2011)

[28] Q. Wang, Y. Gao, J. Luo, Z. Zhong, A. Borgna, Z. Guo, D. O'Hare, RSC Adv. 3, 3414 (2013)

[29] G. Chen, S. Qian, X. Tu, X. Wei, J. Zou, L. Leng, S. Luo, Appl. Surf. Sci. 293, 345 (2014)

[30] R. Wang, Z. Yang, RSC Adv. 3, 19924 (2013)

[31] B. Hai, Y. Zou, Sensors Actuators B-Chem. 208, 143 (2015)

[32] G. Abellán, C. Martí-Gastaldo, A. Ribera, E. Coronado, Acc. Chem. Res. 48, 1601 (2015)

[33] M. Shao, R. Zhang, Z. Li, M. Wei, D.G. Evans, X. Duan, Chem. Commun. 51, 15880 (2015)

[34] K. Abderrazek, F.S. Najoua, E. Srasra, Appl. Clay Sci. 119, 229 (2016)

[35] N. Nakamoto, Infrared and Raman Spectra of Inorganic and Coordination Compounds, 4th edn. (Wiley, New York, 1986)

[36] A. Vaccari, Appl. Clay Sci. 14, 161 (1999)

[37] S. Miyata, Clays Clay Miner. 23, 369 (1995)

[38] F.M. Labajos, V. Rives, M.A. Ulibarri, J. Mater. Sci. 27, 1546 (1992)

[39] H. Hansen, C. Koch, Appl. Clay Sci. 10, 5 (1995)

[40] M. Ogawa, T. Ishiic, N. Miyamotoc, K. Kuroda, Appl. Clay Sci. 22, 179 (2003)

[41] N. Ahmed, Y. Shibata, T. Taniguchi, Y. Izumi, J. Catal. 279, 123 (2011)

[42] J.I. Pankove, Optical Processes in Semiconductor (PrenticeHall, Englewood Cliffs, 1971)

[43] P.A. Wolf, Phys. Rev. 126, 405 (1962) 